\title{
Structure and Capacitive Properties of Porous Nanocrystalline VN Prepared by Temperature-Programmed Ammonia Reduction of $\mathrm{V}_{2} \mathrm{O}_{5}^{\dagger}$
}

\author{
Alexey M. Glushenkov, ${ }^{*}$.\$ Denisa Hulicova-Jurcakova, ${ }^{\S}$ David Llewellyn,, Gao Qing Lu, ${ }^{\S}$ \\ and Ying Chen** \\ *Institute for Technology Research and Innovation, Geelong Technology Precinct, Waurn Ponds, \\ Deakin University, VIC 3217 Australia, ${ }^{\S}$ A RC Centre of Excellence for Functional Nanomaterials, School of \\ Engineering and Australian Institute for Bioengineering and Nanotechnology, The University of Queensland, \\ St. Lucia, QLD 4072 Australia, and "Department of Electronic Materials Engineering, Research School of \\ Physics and Engineering, The Australian National University, Canberra, ACT 0200 Australia
}

Received June 22, 2009. Revised Manuscript Received August 6, 2009

\begin{abstract}
Vanadium nitride (VN) is currently one of the most promising materials for electrodes of supercapacitors. The structure and electrochemical properties of VN synthesized by temperatureprogrammed $\mathrm{NH}_{3}$ reduction of $\mathrm{V}_{2} \mathrm{O}_{5}$ are analyzed in this paper. Vanadium nitride produced via this route has distinctive structural characteristics. $\mathrm{VN}$ mimics the shape of the initial $\mathrm{V}_{2} \mathrm{O}_{5}$ precursor indicating a pronounced direct attachment of nitride grains. The particles have domains of grains with a preferential orientation (texture). The large volume of pores in $\mathrm{VN}$ is represented by the range of 15-110 nm. VN demonstrates capacitive properties in three different types of aqueous electrolytes, $1 \mathrm{M} \mathrm{KOH}, 1 \mathrm{M} \mathrm{H}_{2} \mathrm{SO}_{4}$, and $3 \mathrm{M} \mathrm{NaCl}$. The material has an acceptable rate capability in all electrolytes, showing about $80 \%$ of its maximal capacitance at a current load of $1 \mathrm{~A} / \mathrm{g}$ in galvanostatic charging/discharging experiments. The capacitance of $186 \mathrm{~F} / \mathrm{g}$ is observed in $1 \mathrm{M} \mathrm{KOH}$ electrolyte at $1 \mathrm{~A} / \mathrm{g}$. The previously reported negative effect of material loading on the capacitance is significantly suppressed. The observed electrochemical characteristics related to the application of this material in supercapacitors can be correlated with the crystalline structure of the nitride and the composition of its surface layer.
\end{abstract}

\section{Introduction}

Supercapacitors (also known as electrochemical capacitors and ultracapacitors) are a class of electrochemical energy storage devices that complement batteries. They are capable of providing quick charge release when it is needed and normally have a much longer cycle life than batteries. ${ }^{1,2}$ The current areas of applications of supercapacitors include power back-up devices, portable electronics, emergency doors of aircrafts, and hybrid and electric cars. ${ }^{3-5}$ Conventional electrochemical electric double layer capacitors (EDLC) utilize the charge storage by adsorption of ions at the surface of electrodes composed of graphitic carbons with huge surface areas. ${ }^{1,2,6}$

A novel class of materials (including some inorganic compounds and conductive polymers) has been proposed

\footnotetext{
† Accepted as part of the 2010 "Materials Chemistry of Energy Conversion Special Issue".

*Corresponding authors. Tel: +613 52272931,e-mail: alexey.glushenkov@ deakin.edu.au (A.M.G.). Tel.: +61 3 52273243, e-mail: ian.chen@deakin.edu. au (Y.C.). Previous address: Department of Electronic Materials Engineering, Research School of Physics and Engineering, the Australian National University, Canberra, ACT 0200.

(1) Conway, B. E. Electrochemical supercapacitors, scientific fundamentals and technological applications; Kluwer Academic/Plenum Publisheers: New York, 1999.

(2) Simon, P.; Gogotsi, Y. Nat. Mater. 2008, 7, 845.

(3) Kötz, P.; Carlen, M. Electrochim. Acta 2000, 45, 2483.

(4) Miller, J. R.; Burke, A. F. Electrochem. Soc. Interface 2008, 17, 53.

(5) Miller, J. R.; Simon, P. Science 2008, 321, 651.

(6) Pandolfo, A. G.; Hollenkamp, A. F. J. Power Sources 2006, 157, 11.
}

in the past decade for the applications in electrodes of supercapacitors. ${ }^{1,2}$ These materials possess the so-called pseudocapacitance, that is, most of the charge is stored not by the conventional EDL mechanism but is due to the presence of fast redox reactions on the surface of these materials. The use of pseudocapacitive nanoscale transition metal oxides and nitrides has been named one of the three greatest achievements in the field of supercapacitors in the most recent review paper ${ }^{2}$. Hydrous $\mathrm{RuO}_{2}$ is currently a benchmark pseudocapacitive material. ${ }^{1,7}$ It is capable of demonstrating capacitances exceeding $1000 \mathrm{~F} / \mathrm{g}$ but is extremely expensive. Research in the area of pesudocapacitors is focused on finding a cheaper alternative to ruthenium oxide. Among other possible materials, vanadium nitride (VN) is currently one of the most promising candidates.

VN has been found to deliver a specific capacitance of up to $1340 \mathrm{~F} / \mathrm{g}$ in $1 \mathrm{M} \mathrm{KOH}$ aqueous electrolyte when a thin film of this material $\left(0.25 \mathrm{mg} / \mathrm{cm}^{2}\right)$ was assessed by cyclic voltammetry at a sweep rate of $2 \mathrm{mV} / \mathrm{s}^{8,9}$ The impressive performance has been attributed to the

(7) Hu, C. C.; Chang, K. H.; Lin, M. C.; Wu, Y. T. Nano Lett. 2006, 6, 2690.

(8) Choi, D.; Kumta, P. N. Electrochem. Solid State Lett. 2005, 8, A418.

(9) Choi, D.; Blomgren, G. E.; Kumta, P. N. Adv. Mater. 2006, 18, 1178 . 
combination of high electronic conductivity of vanadium nitride and redox reactions provided by few layers of vanadium oxides or oxynitrides on the surface. The material acts as a core-shell composite, in which the surface layer is responsible for high pseudocapacitance and the nitride core is responsible for quick electron transport.

Vanadium nitrides for testing in supercapacitor cells were prepared by a chemical route based on a two-step ammonolysis reaction of $\mathrm{VCl}_{4}$ in anhydrous chloroform. ${ }^{8,9}$ A disadvantage of $\mathrm{VN}$ materials prepared in this way is their limited rate capability. The initially impressive capacitance (at low sweep rates in cyclic voltammetry) has been observed to fade significantly when the sweep rate is increased. The effect of material loading, which is possibly related to the poor rate capability, was also reported. ${ }^{9}$ The essence of this effect is that when the amount of material per unit of area of the current collector is increased the capacitances decrease dramatically. Only thin films (with VN densities below $1 \mathrm{mg} / \mathrm{cm}^{2}$ ) could deliver attractive capacitances.

The primary explanation is a decreased electronic conductivity of nanocrystalline $\mathrm{VN}$ which consists of weakly interconnected nanoparticles and a limited ionic conductivity of the electrolyte due to the porous structure of the electrode with small pores. The estimated conductivity of nanocrystalline VN was two- to threefold smaller than that of a bulk material. ${ }^{8}$ To achieve an improved rate capability for a nanostructured VN and suppress the dramatic dependence of its capacitance on material loading, an appropriate crystalline structure of a nanostructured vanadium nitride involving well-connected nanoparticles and optimized porosity has to be designed.

Temperature-programmed ammonia reduction of $\mathrm{V}_{2} \mathrm{O}_{5}$ is a simpler alternative procedure to produce porous VN. It has been previously used for the preparation of vanadium nitride catalysts with high surface areas. ${ }^{10-12}$ Unlike an approach used in refs 8 and 9 , this procedure involves only one step and does not require special equipment (a glovebox and a glovebag). Kwon et al. ${ }^{10}$ observed that the conversion of $\mathrm{V}_{2} \mathrm{O}_{5}$ into $\mathrm{VN}$ materials is pseudomorphic; that is, the resulting porous nitride retains the morphology of the initial $\mathrm{V}_{2} \mathrm{O}_{5}$. It may be anticipated that the excellent interconnection of grains in such a material would favor better rate capabilities of $\mathrm{VN}$.

In this article, we study the structure and capacitive behavior of $\mathrm{VN}$ materials produced by temperatureprogrammed ammonia reduction of $\mathrm{V}_{2} \mathrm{O}_{5}$. It is shown that these porous textured nitrides demonstrate acceptable rate capabilities in three types of aqueous electrolytes ( $1 \mathrm{M} \mathrm{KOH}, 1 \mathrm{M} \mathrm{H}_{2} \mathrm{SO}_{4}$, and $1 \mathrm{M} \mathrm{NaCl}$ ). The observed performance of $\mathrm{VN}$ is linked to its crystalline structure and the composition of the surface layer.

During the final stages of the manuscript preparation, we have encountered another recently published article

(10) Kwon, H.; Choi, S.; Thompson, L. T. J. Catal. 1999, 184, 236.

(11) Kapoor, R.; Oyama, S. T. J. Solid State Chem. 1992, 99, 303.

(12) Choi, J. G.; Ha, J.; Hong, J. W. Appl. Catal., A 1998, $168,47$. on VN materials for supercapacitors. ${ }^{13}$ The VN materials have been prepared by calcining vanadium oxide xerogel under $\mathrm{NH}_{3}$ atmosphere at $400{ }^{\circ} \mathrm{C}$. We have incorporated a discussion of these recent results into the current paper.

\section{Experimental Section}

The starting material for the synthesis was a commercial $\mathrm{V}_{2} \mathrm{O}_{5}$ powder from Sigma-Aldrich (99.6\% purity). It consisted of relatively large particles (which were, in fact, aggregates of smaller submicrometer particles) with sizes of 200-500 $\mu \mathrm{m}$. Temperature-programmed reduction of $\mathrm{V}_{2} \mathrm{O}_{5}$ by ammonia gas was performed in a tube furnace (Jetlow furnaces, Melbourne, Australia). The $\mathrm{NH}_{3}$ flow of $0.7 \mathrm{~L} / \mathrm{min}$ was passing through the furnace tube. A total of $600 \mathrm{mg}$ of the $\mathrm{V}_{2} \mathrm{O}_{5}$ precursor were loaded inside of the tube. The sample was heated up to $700^{\circ} \mathrm{C}$ at the rate of $2.8^{\circ} \mathrm{C} / \mathrm{min}$ and kept at $700{ }^{\circ} \mathrm{C}$ for $1 \mathrm{~h}$. After that, the furnace cooled down naturally overnight in $\mathrm{NH}_{3}$ flow. The asprepared sample was normally passivated by passing the mixture of $0.1 \% \mathrm{O}_{2}$ and high purity Ar gas over the sample for $2 \mathrm{~h}$.

The original and resulting materials were analyzed by X-ray diffraction (XRD, Philips analytical X-ray spectrometer with Co radiation $\lambda=0.1789 \mathrm{~nm}$ ), scanning electron microscopy (SEM, Hitachi S-4500), and transmission electron microscopy (TEM, Phillips CM300). Surface area and pore size distribution were evaluated using $\mathrm{N}_{2}$ adsorption (Quantachrome instruments Quadrasorb SI). The specific surface area was calculated from the $\mathrm{N}_{2}$ adsorption isotherm using the BranauerEmmett-Teller (BET) equation, and the pore size distribution was obtained from Barrett-Joiner-Helenda (BJH) method.

A special sample of VN was prepared specifically for TEM characterization to study the preferred orientation of grains in the material. The $\mathrm{V}_{2} \mathrm{O}_{5}$ precursor for this sample was different and represented single-crystalline nanorods. The morphology of the nanorods is described in detail elsewhere. ${ }^{14}$ Each singlecrystalline nanorod had a rectangular cross section and was elongated along the [010] crystallographic direction of $\mathrm{V}_{2} \mathrm{O}_{5}$ (see Figure 3 in ref 14).

The X-ray photoelectron spectroscopy (XPS) measurements were performed on ESCALAB220i-XL (VG Scientific, U.K.) using the $\mathrm{Al} \mathrm{K} \alpha$ source. The binding energy scale in the XPS measurements was corrected for the charging effect by assigning a value of $284.6 \mathrm{eV}$ to the $\mathrm{C} 1 \mathrm{~s}$ peak of adventitious carbon. $\mathrm{O} 1 \mathrm{~s}$ and $\mathrm{V} 2 \mathrm{p}^{3}$ lines in the XPS spectra were fitted with several peaks using free XPSPeak 4.1 software. Initial peak positions of 514.1, $515.6,516.5$, and $517.3 \mathrm{eV}$ were used for fitting the $\mathrm{V} 2 \mathrm{p}^{3}$ line (these values correspond to typical positions of the $\mathrm{V} 2 \mathrm{p}^{3}$ line in $\mathrm{VN}, \mathrm{V}_{2} \mathrm{O}_{3}, \mathrm{VO}_{2}$, and $\mathrm{V}_{2} \mathrm{O}_{5}$, see main text of the article for more details). The number of peaks, shapes, and positions of them were optimized for the best fit.

Three-electrode cells were assembled to assess the electrochemical properties of vanadium nitride. The working electrode was prepared by mixing the VN (80 wt \%), carbon black (Mitsubishi \#32, $10 \mathrm{wt} \%$ ), and polyvinylidene fluoride (PVDF, 10 wt \%) in $N$-methyl-2-pyrrolidone (NMP). The resulting slurry was spread onto pieces of titanium foil. $\mathrm{Pt}$ electrode was used as a counter electrode and $\mathrm{Ag} / \mathrm{AgCl}$ as a reference electrode. The cyclic voltammetry $(\mathrm{CV})$ and galvanostatic charge/discharge (GC) tests were performed in $3 \mathrm{M} \mathrm{NaCl}$, $1 \mathrm{M} \mathrm{KOH}$, and $1 \mathrm{M} \mathrm{H}_{2} \mathrm{SO}_{4}$ aqueous electrolytes. Capacitances

(13) Zhou, X. P.; Chen, H. Y.; Shu, D.; He, C.; Nan, J. M. J. Phys. Chem. Solids 2009, 70, 495 .

(14) Glushenkov, A. M.; Stukachev, V. I.; Hassan, M. F.; Kuvshinov, G. G.; Liu, H. K.; Chen, Y. Cryst. Growth Des. 2008, 8, 3661. 


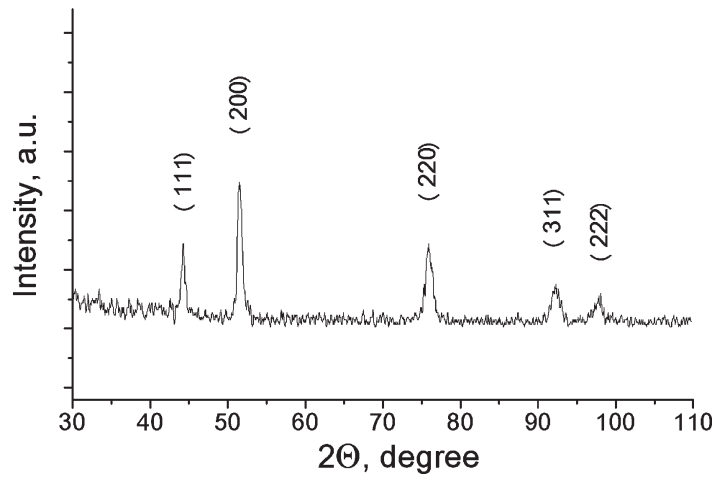

Figure 1. XRD pattern of $\mathrm{VN}$ produced by $\mathrm{NH}_{3}$ reduction of $\mathrm{V}_{2} \mathrm{O}_{5}$.
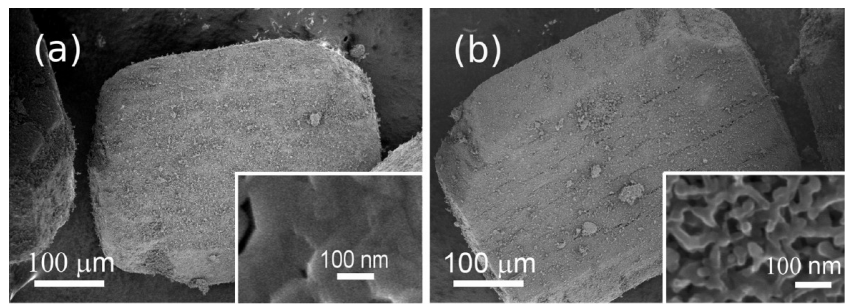

Figure 2. SEM characterization: a typical particle of the commercial $\mathrm{V}_{2} \mathrm{O}_{5}$ powder (a) and a particle in the resulting $\mathrm{VN}(\mathrm{b})$. Insets show highmagnification images of particles.

were calculated from the discharge branches of galvanostatic charge/discharge curves and areas enclosed by cyclic voltammetry curves. The used $\mathrm{Ag} / \mathrm{AgCl}$ reference electrode could withstand the alkaline electrolyte since it was not the standard $\mathrm{Ag} / \mathrm{AgCl}$ with the porous glass tip (that dissolves in concentrated $\mathrm{KOH}$ ) but the special $\mathrm{Ag} / \mathrm{AgCl}$ designed for acidic as well as basic electrolytes.

\section{Results and Discussion}

Structural Characterization. Figure 1 shows an XRD pattern of the sample obtained by temperature-programmed $\mathrm{NH}_{3}$ reduction of the $\mathrm{V}_{2} \mathrm{O}_{5}$ powder. The positions of diffraction peaks in the pattern are close to those of cubic vanadium nitride (PDF file 73-0528). The peaks are broadened, indicating a small size of individual crystallites.

SEM images of the initial $\mathrm{V}_{2} \mathrm{O}_{5}$ powder and the resulting VN sample are shown in Figure 2. A typical particle of the commercial $\mathrm{V}_{2} \mathrm{O}_{5}$ powder is demonstrated in Figure 2a, and Figure $2 \mathrm{~b}$ depicts a representative $\mathrm{VN}$ particle obtained by the $\mathrm{NH}_{3}$ reduction. The high-magnification SEM images in the insets show that the VN particle has a porous nature with typical pore sizes below $100 \mathrm{~nm}$ while the initial $\mathrm{V}_{2} \mathrm{O}_{5}$ particle does not have a pronounced porous structure. It can be concluded from SEM analysis that the $\mathrm{NH}_{3}$ reduction of $\mathrm{V}_{2} \mathrm{O}_{5}$ powders leads to the conservation of the overall particles' shapes and sizes while the interior of particles becomes porous. The conservation of the external shape is presumed to be due to a strong direct attachment of grains in the resulting nitrides. The VN particles can be interpreted as porous frameworks built with interconnected crystalline fragments.

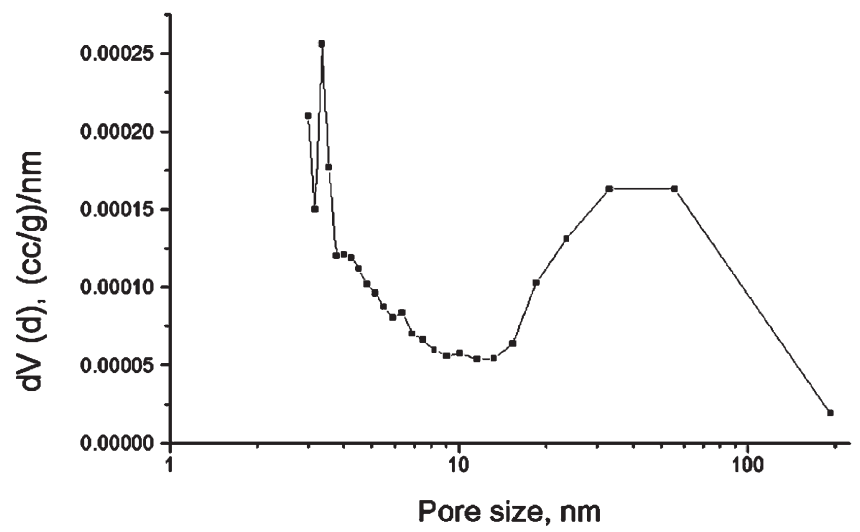

Figure 3. Pore size distribution of the VN sample produced.

The pore size distribution of vanadium nitride is shown in Figure 3. It is dominated mostly by pores in the range of 15-110 nm (the broad peak on the right-hand side of the distribution), but some smaller pores are also present. The measured BET surface area of the sample was $22.9 \mathrm{~m}^{2} / \mathrm{g}$. It is smaller than some reported values, ${ }^{10,11}$ which can be correlated to the fact that vanadium nitrides were prepared using a "licked" bed of material (the gas flow was passing above the layer of the oxide powder in the furnace tube).

Figure 4 shows the results of TEM characterization of a fragment of a VN particle. The electron diffraction pattern is in the form of discontinuous rings (Figure 4a). The grainy contrast in the bright-field image (Figure 4b) confirms the nanocrystalline structure of the material. The dark-field image recorded using the diffracted beam (emphasized with a circle in Figure 4a) is depicted in Figure 4c. Specifically, it reveals the area in the nanocrystalline agglomerate consisting of the grains with similar orientations. These grains give a noticeable bright contrast in the dark-field image, and the corresponding area is shown with arrows.

To evaluate the nature of the preferential grain orientation, additional TEM work has been conducted. A special sample of $\mathrm{VN}$ has been prepared by $\mathrm{NH}_{3}$ reduction of single-crystalline $\mathrm{V}_{2} \mathrm{O}_{5}$ nanorods. The detailed characterization of the crystalline structure of this $\mathrm{V}_{2} \mathrm{O}_{5}$ sample can be found in ref 14. Briefly, each $\mathrm{V}_{2} \mathrm{O}_{5}$ nanorod was elongated along the [010] crystallographic direction and had a rectangular cross section defined by $\{001\}$ and $\{100\}$ crystal planes (see Figure 3 in ref 14). The SEM image of the $\mathrm{V}_{2} \mathrm{O}_{5}$ nanorods is shown in Figure 5a. Porous VN nanorods obtained by $\mathrm{NH}_{3}$ reduction of them are shown in Figure 5b. These VN nanorods are an ideal sample to investigate the internal structure of $\mathrm{VN}$ by TEM and relate it to the structure of initial $\mathrm{V}_{2} \mathrm{O}_{5}$ crystals.

The diffraction pattern of a VN nanorod (Figure $5 \mathrm{c}$ ) is similar to that of a single crystal. However, each diffraction spot is converted into an arc, which is an evidence of texture in the polycrystalline structure. In other words, there exists a preferential orientation of grains (crystallites) in each nanorod of VN. It follows from the analysis of the diffraction pattern that the [110] direction of VN tends to be parallel to the [010] direction in the initial 

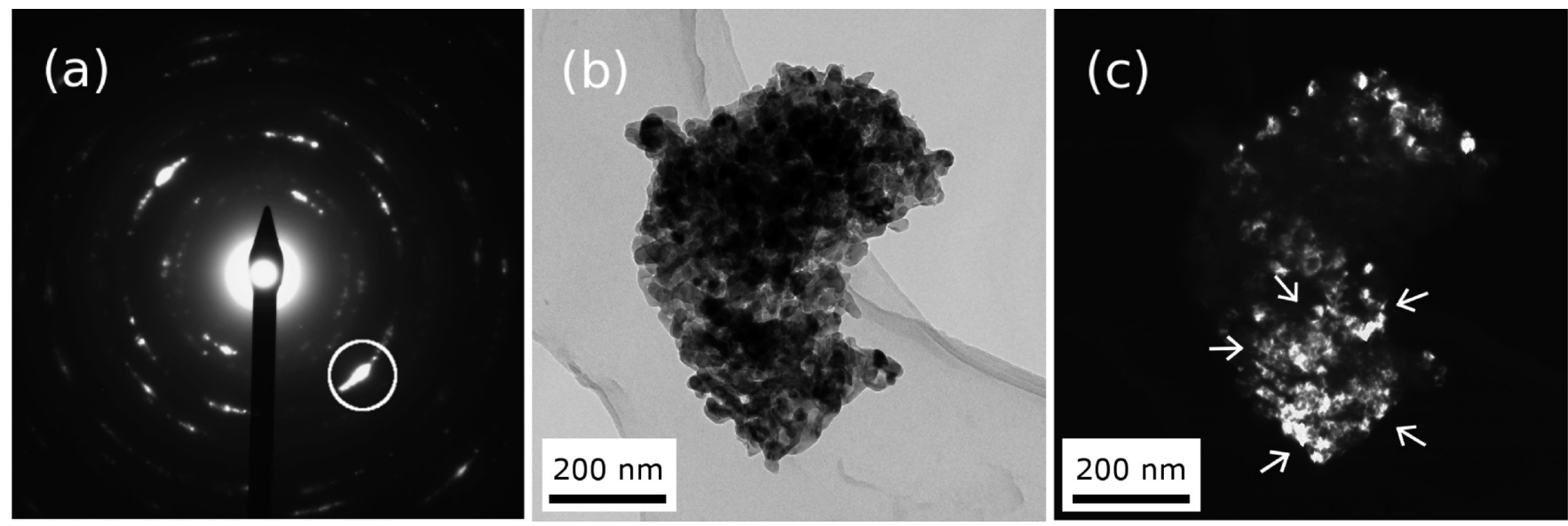

Figure 4. TEM characterization: (a, b) SAED pattern and bright-field image of a piece of a VN particle; (c) dark-field image taken using the diffracted beam shown with a circle in (a). The arrows in (c) show the area consisting of grains with similar crystalline orientations.

$\mathrm{V}_{2} \mathrm{O}_{5}$, and disorientation of grains happens mainly by a rotation around the [001] direction of the original $\mathrm{V}_{2} \mathrm{O}_{5}$ crystal. When the 200 diffracted beam was selected to form a dark-field image (Figure 5d), we could observe numerous groups of grains with contrast similar to that detected in VN particles (Figure 4c). Figure 5e is a highresolution image taken from two adjacent crystallites in the nanorod. Two sets of (200) planes of VN are rotated slightly in respect to each other around the former [001] direction of $\mathrm{V}_{2} \mathrm{O}_{5}$, and the FFT pattern of the image (Figure 2f) shows that even more clearly. Two pairs of spots can be seen, rotated in relation to each other by a small angle. The situation in the large $\mathrm{VN}$ particles (which we discuss in this article) is more complicated since the original $\mathrm{V}_{2} \mathrm{O}_{5}$ precursor is polycrystalline. However, it is likely that individual single-crystalline areas within each particle are converted into textured domains of grains in the course of $\mathrm{NH}_{3}$ reduction.

In summary, the $\mathrm{VN}$ material produced by $\mathrm{NH}_{3}$ reduction of $\mathrm{V}_{2} \mathrm{O}_{5}$ possesses the following structural characteristics: (1) individual grains in each particle are directly attached to each other; (2) the particles have crystalline domains with a preferential orientation of grains (texture); and (3) a large volume of pores is in the range of $15-110 \mathrm{~nm}$.

Electrochemical Properties. Vanadium nitride has shown capacitive properties in all electrolytes tested-1 $\mathrm{M} \mathrm{H}_{2} \mathrm{SO}_{4}$, $1 \mathrm{M} \mathrm{KOH}$, and $3 \mathrm{M} \mathrm{NaCl}$. The corresponding $\mathrm{CV}$ curves of $\mathrm{VN}$ at the sweep rates of 5 and $100 \mathrm{mV} / \mathrm{s}$ are depicted in Figure 6 . The suitable voltage windows are defined as -0.2 to $0.6 \mathrm{~V}$ for $1 \mathrm{M} \mathrm{H}_{2} \mathrm{SO}_{4}$ and $3 \mathrm{M} \mathrm{NaCl}$ and -1.2 to $0 \mathrm{~V}$ for $1 \mathrm{M} \mathrm{KOH}$ vs $\mathrm{Ag} / \mathrm{AgCl}$ reference electrode. The voltage window of $1.2 \mathrm{~V}$ in $1 \mathrm{M} \mathrm{KOH}$ solution is the same as was previously reported. ${ }^{8,9}$ The ordinate axes in Figure 6 represent differential capacitances (specific currents divided by the sweep rates), and such a representation visualizes directly the comparison of capacitances at various sweep rates.

The capacitive properties in $1 \mathrm{M} \mathrm{H}_{2} \mathrm{SO}_{4}$ and $3 \mathrm{M} \mathrm{NaCl}$ aqueous solutions are evaluated for the first time. The presence of significant redox peaks in cyclic voltammograms undoubtedly confirms pseudocapacitance in both the acidic and neutral electrolytes. However, the investigation of the exact pseudocapacitive interactions in $3 \mathrm{M}$
$\mathrm{NaCl}$ and $1 \mathrm{M} \mathrm{H}_{2} \mathrm{SO}_{4}$ is beyond the scope of the current paper, and we plan to address that in a future publication. It is obvious that VNs have reasonably good rate capabilities in $1 \mathrm{M} \mathrm{KOH}$ since the area enclosed by the CV curve does not fall dramatically when the sweep rate is increased from 5 to $100 \mathrm{mV} / \mathrm{s}$. Poor rate capabilities were found to be a disadvantage of VN electrodes for supercapacitors, ${ }^{8}$ and it is apparent that VN materials produced by $\mathrm{NH}_{3}$ reduction of $\mathrm{V}_{2} \mathrm{O}_{5}$ can improve the high rate performance.

It has been indicated previously ${ }^{9}$ that the performance of vanadium nitrides in $1 \mathrm{M} \mathrm{KOH}$ in $\mathrm{CV}$ experiments was also dependent strongly on the material density on the current collector. When the material loading per unit of area of the current collector was increased, the capacitance of VN dropped and rate capabilities degraded noticeably. For example, the capacitance of vanadium nitride with the density of $0.99 \mathrm{mg} / \mathrm{cm}^{2}$ was almost twice smaller than that of VN with the density of $0.25 \mathrm{mg} / \mathrm{cm}^{2}$ at the $\mathrm{CV}$ scan rate of $2 \mathrm{mV} / \mathrm{s}$ and became 5 times smaller at the sweep rate of $100 \mathrm{mV} / \mathrm{s}^{9}$ In the present study, vanadium nitride is prepared by a different approach, $\mathrm{NH}_{3}$ reduction of $\mathrm{V}_{2} \mathrm{O}_{5}$, and the dependence of the capacitances and rate capabilities on the material loading is weak and does not demonstrate a dramatic decrease with the increase in the material's density. For example, electrodes with densities of 1.1 and $0.55 \mathrm{mg} / \mathrm{cm}^{2}$ demonstrated similar capacitances in $1 \mathrm{M} \mathrm{KOH}(101$ and $105 \mathrm{~F} / \mathrm{g}$ at the $\mathrm{CV}$ sweep rate of $5 \mathrm{mV} / \mathrm{s}$ ). Furthermore, the vanadium nitrides in this study can retain acceptable rate capabilities at high material loadings on a current collector. The rate capabilities shown in Figure 6, for example, were measured using thick films of VN (with densities of about $4-6 \mathrm{mg} / \mathrm{cm}^{2}$ ).

The improved rate capability and the minimized dependence of capacitance on the density of the material on a current collector is likely to be due to the structural features of $\mathrm{VN}$ synthesized by $\mathrm{NH}_{3}$ reduction of $\mathrm{V}_{2} \mathrm{O}_{5}$. These features are clearly different from those in nitrides synthesized by Choi et al., ${ }^{8,9}$ whose material consisted of rather weakly connected nanoparticles with no preferential orientation and the typical pore sizes of $3-40 \mathrm{~nm}$. The 

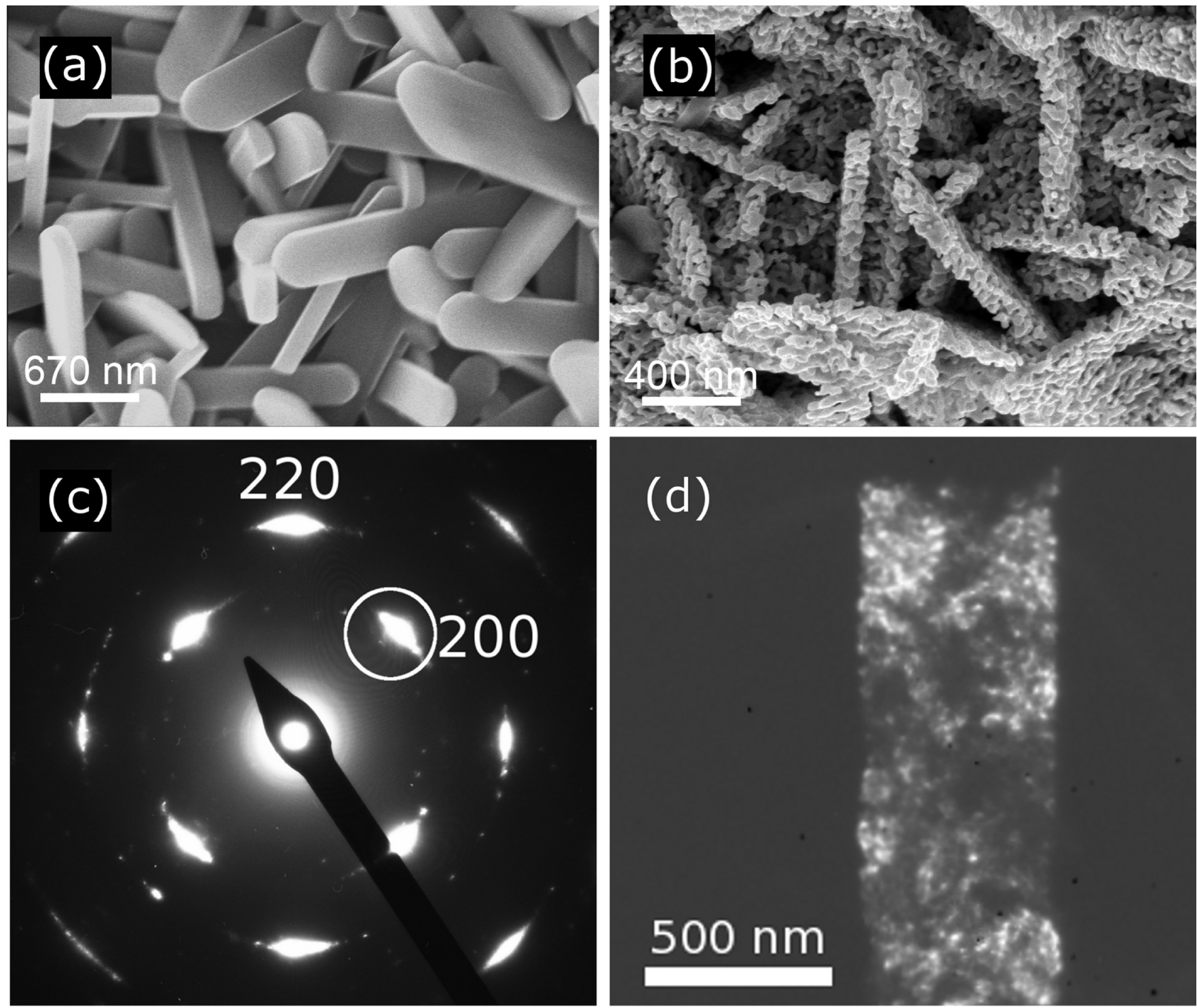

(d)

\section{$500 \mathrm{~nm} \quad \mathrm{~s} / \mathrm{s}$}

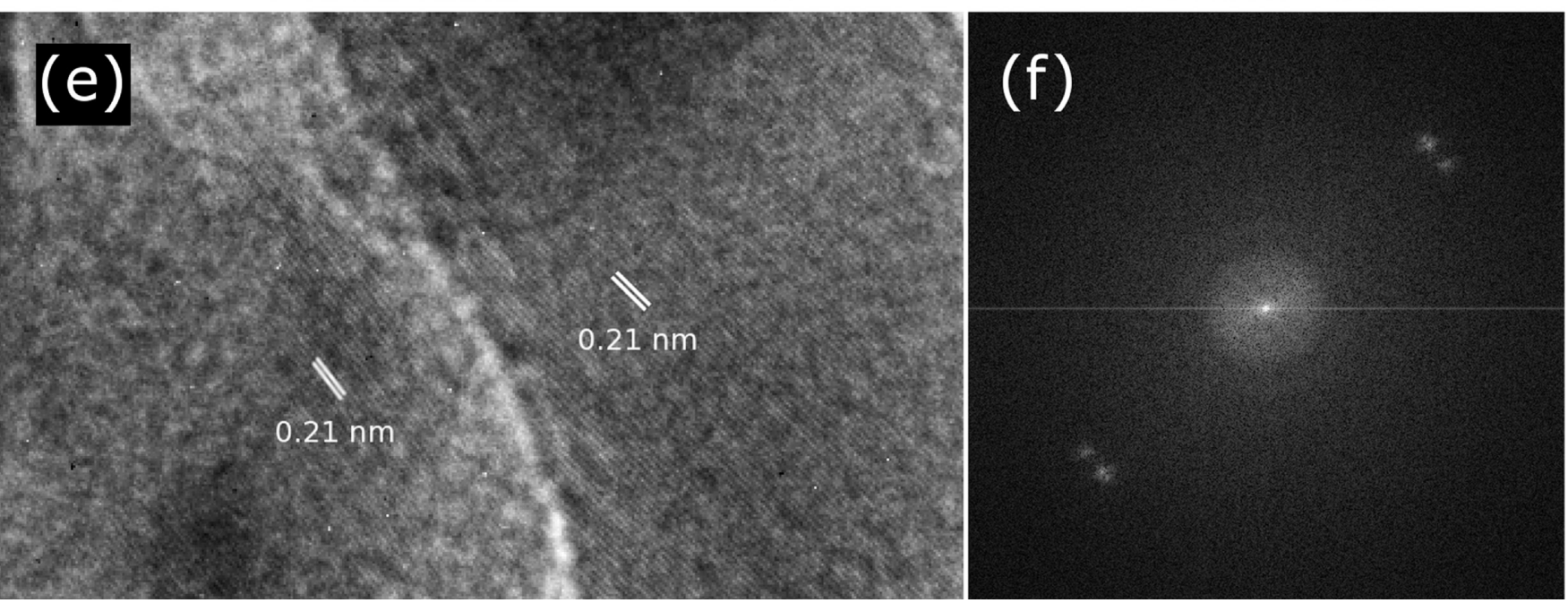

Figure 5. Electron microscopy study of the preferred grain orientation in vanadium nitride. A special sample of VN is produced from single-crystalline nanorods of $\mathrm{V}_{2} \mathrm{O}_{5}$. (a, b) SEM images of the initial $\mathrm{V}_{2} \mathrm{O}_{5}$ nanorods and the resulting porous nanorods of VN. (c, d) SAED pattern and dark-field image of a VN nanorod. (e, f) High-resolution image of two adjacent grains and its FFT pattern.

VN particles synthesized in our study are well-connected polycrystalline porous frameworks, and this leads to their higher electronic conductivity. The conductivity is possi- bly further improved by the presence of textured domains (i.e., areas with preferential grain orientations) in the particles. As a result of the better electrical conductivity, 

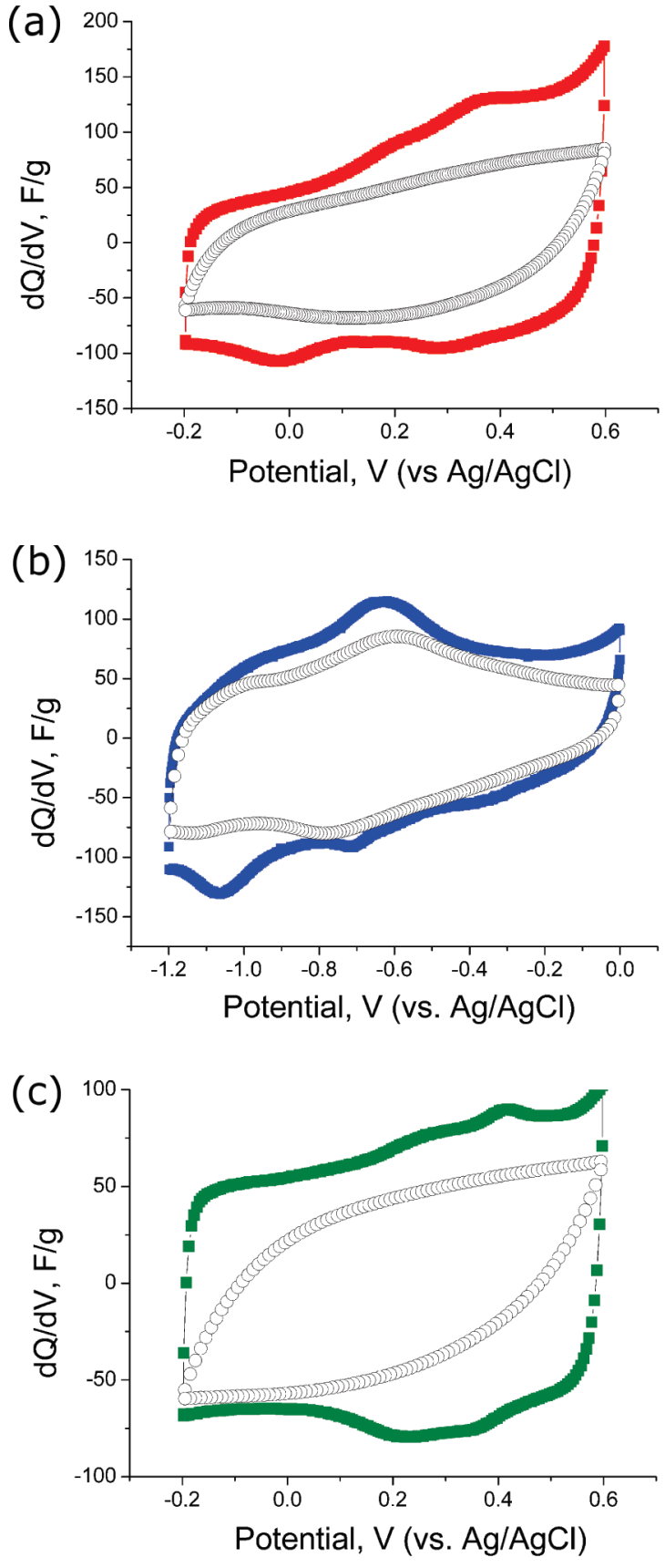

Figure 6. $\mathrm{CV}$ curves of vanadium nitride in $1 \mathrm{M} \mathrm{H}_{2} \mathrm{SO}_{4}$ (a), $1 \mathrm{M} \mathrm{KOH}(\mathrm{b})$, and $3 \mathrm{M} \mathrm{NaCl}$ (c) aqueous electrolytes at the sweep rate of $5 \mathrm{mV} / \mathrm{s}$ (colored solid symbols) and $100 \mathrm{mV} / \mathrm{s}$ (gray open symbols).

the $\mathrm{VN}$ performs reasonably well at higher sweep rates or charging/discharging rates. The thickness of the film is also no longer a critical parameter limiting the use of larger amounts of the active material in an electrode.

Generally, our results are in a good agreement with the results of a recent publication by Zhou et al. ${ }^{13}$ who produced vanadium nitrides by calcining vanadium oxide xerogel under $\mathrm{NH}_{3}$ atmosphere at $400{ }^{\circ} \mathrm{C}$. The capacitance of $161 \mathrm{~F} / \mathrm{g}$ has been measured at $30 \mathrm{mV} / \mathrm{s}$ by cyclic voltammetry. The ammonia reduction of hydrous vanadium oxide is a process similar to ours, and somewhat similar structural characteristics of vanadium nitride can be expected. The authors, however, have brought forward a different explanation of the good capacitance retention (a)

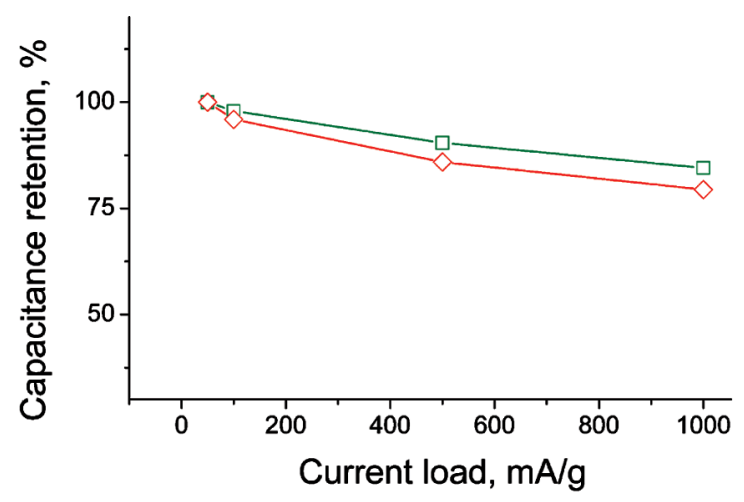

(b)

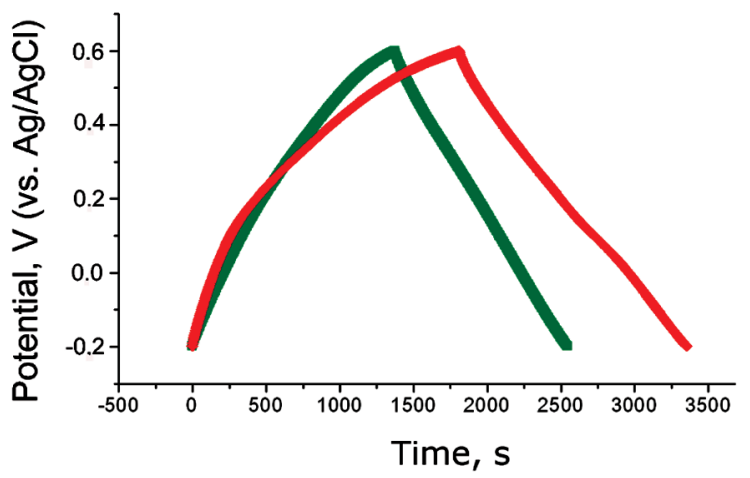

(c)

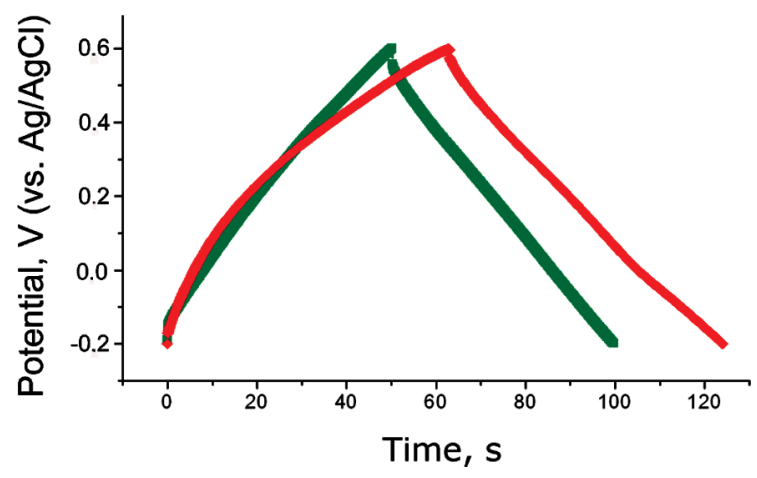

Figure 7. Rate capability of vanadium nitride. (a) Capacitance retention at various current loads. (b, c) Charge/discharge curves at the current loads of $50 \mathrm{~mA} / \mathrm{g}$ and $1 \mathrm{~A} / \mathrm{g}$, respectively. Red curves (rhombs) correspond to $1 \mathrm{M} \mathrm{H}_{2} \mathrm{SO}_{4}$ electrolyte and green curves (squares) correspond to $3 \mathrm{M} \mathrm{NaCl}$ electrolyte.

at high current loads or voltage sweep rates. According to their interpretation, the good capacitance retention should be explained by the dominance of fast, reversible redox reactions at the surface with only small contribution from slow or irreversible processes. Meanwhile, we believe that the improvement in rate capability is mainly due to the crystalline structure of the nitride.

The capacitance retention by our VN material acceptable for applications in supercapacitors is confirmed by galvanostatic charge/discharge experiments (Figure 7a). When it is charged and discharged at the current load of $1 \mathrm{~A} / \mathrm{g}$, the VN sample demonstrates $79 \%$ of the capacitance measured at $50 \mathrm{~mA} / \mathrm{g}$ in $1 \mathrm{M} \mathrm{H}_{2} \mathrm{SO}_{4}$ and $84 \%$ of the initial capacitance in $3 \mathrm{M} \mathrm{NaCl}$ electrolyte. Figure $7 \mathrm{~b}, \mathrm{c}$ shows the charge/discharge curves of $\mathrm{VN}$ in $1 \mathrm{M} \mathrm{H}_{2} \mathrm{SO}_{4}$ and $3 \mathrm{M} \mathrm{NaCl}$ electrolytes at the current loads of $50 \mathrm{~mA} / \mathrm{g}$ and $1 \mathrm{~A} / \mathrm{g}$. The curves have a triangular shape close to an 


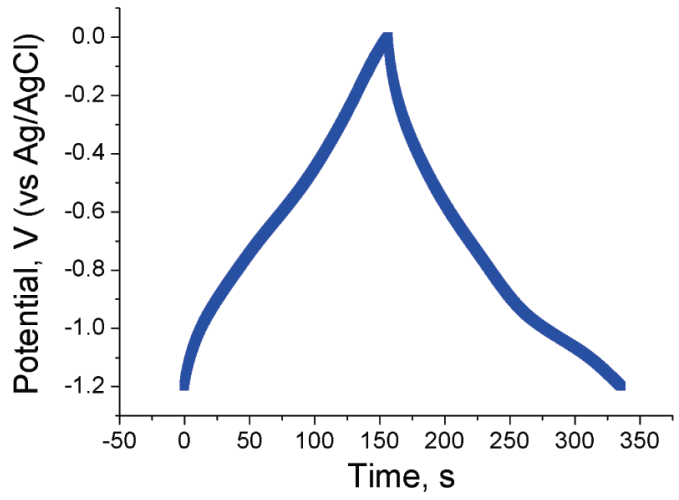

Figure 8. Charge/discharge curve of $\mathrm{VN}$ at the current of $1 \mathrm{~A} / \mathrm{g}$ in $1 \mathrm{M}$ $\mathrm{KOH}$ electrolyte.

ideal one at both current rates, and only a minor IR drop is detected in the GC curves when the current of $1 \mathrm{~A} / \mathrm{g}$ is switched to the opposite value. The time of charge and discharge is longer in $1 \mathrm{M} \mathrm{H}_{2} \mathrm{SO}_{4}$ since vanadium nitride demonstrates higher capacitances in this electrolyte.

The highest capacitance measured at $1 \mathrm{~A} / \mathrm{g}$ was $186 \mathrm{~F} / \mathrm{g}$ ( $82 \%$ of the maximal capacitance) in $1 \mathrm{M} \mathrm{KOH}$ electrolyte (the charge/discharge profile is given in Figure 8). To obtain this value, the sample was additionally annealed in air at $200^{\circ} \mathrm{C}$ after the synthesis to modify the composition of the surface layer. The corresponding maximal capacitance $(225 \mathrm{~F} / \mathrm{g})$ has been achieved at $500 \mathrm{~mA} / \mathrm{g}$ and correlates well with the value of capacitance $(221 \mathrm{~F} / \mathrm{g})$ measured by $\mathrm{CV}$ at a slow sweep rate of $5 \mathrm{mV} / \mathrm{s}$. It has been observed that the $\mathrm{VN}$ electrodes fail to charge and discharge in $1 \mathrm{M} \mathrm{KOH}$ at low current densities (50 and, in some cases, $100 \mathrm{~mA} / \mathrm{g}$ ). This phenomenon manifests itself as extremely long charge or discharge branches in GC curves. At this stage, we do not have a convincing explanation for such behavior.

The observed maximal capacitances of vanadium nitrides in our paper and in recent publication of Zhou et al. ${ }^{13}$ are lower than those reported previously by Choi et al. ${ }^{8,9}$ and can be related to a different composition of the surface layer. The amount of oxygen at the surface of vanadium nitride is likely to be an important parameter affecting the capacitance of the material. X-ray photoelectron spectroscopy was applied to probe the surface chemistry of vanadium nitride. The XPS technique is an effective tool to study the composition of a surface layer of materials (2-4 $\mathrm{nm}$ in depth). It allows one to determine the presence of elements at the surface, estimate their content quantitatively, and in some cases, study the depth profile of elemental composition at the surface of the samples. ${ }^{15}$ If a particular element exhibits different oxidation states, the XPS technique is capable of distinguishing between them. Great care, however, has to be exercised to determine the presence of vanadium in different oxidation states since the binding energies (BE) of $\mathrm{V} 2 \mathrm{p}^{3}$ line (which is normally used) for vanadium oxides with various oxidation states of vanadium $\left(\mathrm{V}_{2} \mathrm{O}_{5}, \mathrm{VO}_{2}\right.$, and $\mathrm{V}_{2} \mathrm{O}_{3}$, corresponding to

(15) Briggs, S.; Seah, M. P. Practical surface analysis; Wiley: New York, 1990; Vol. 1.

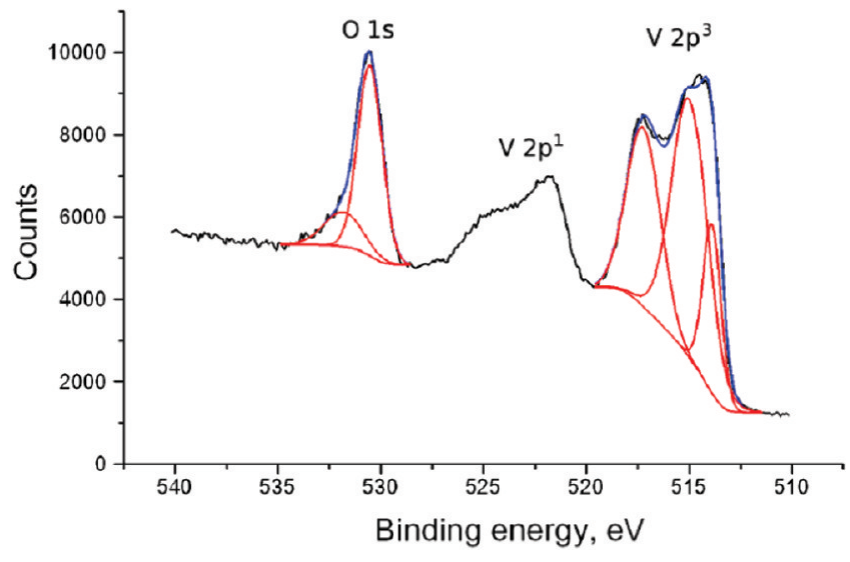

Figure 9. XPS spectrum of the surface of VN.

$\mathrm{V}^{5+}, \mathrm{V}^{4+}$, and $\mathrm{V}^{3+}$ ) are in a narrow range of about $515.5-517.5 \mathrm{eV} .{ }^{16}$ The situation is further complicated since a range of $\mathrm{BE}$ values is reported for each oxidation state of vanadium possibly because of equipment calibration differences and inaccuracy of the correction for sample charging. ${ }^{17}$

Bondarenka et al. ${ }^{17}$ have conducted a useful statistical analysis of XPS literature data on the binding energies of $\mathrm{V} 2 \mathrm{p}^{3}$ lines for vanadium in different oxidation states. The reported binding energies for $\mathrm{V}^{5+}, \mathrm{V}^{4+}$, and $\mathrm{V}^{3+}$ species were found to correspond to three Gaussian distributions centered at 517.3, 516.5, and $515.6 \mathrm{eV}$, respectively, with the statistical deviation $\mathrm{W}_{\mathrm{BE}}=0.25 \mathrm{eV}$. In other words, the reported binding energies for $\mathrm{V}^{5+}, \mathrm{V}^{4+}$, and $\mathrm{V}^{3+}$ species are in the ranges $517.3 \pm 0.25,516.5 \pm 0.25$, and $515.6 \pm 0.25 \mathrm{eV}$ with a probability of $70 \%$ and within the ranges $517.3 \pm 0.5,516.5 \pm 0.5$, and $515.6 \pm 0.5 \mathrm{eV}$ with a probability of $95 \% .{ }^{17}$ A careful data analysis is therefore possible for the reliable qualitative separation of vanadium species in different oxidation states.

The XPS spectrum of VN passivated with $0.1 \% \mathrm{O}_{2}$ in $\mathrm{Ar}$ gas is shown in Figure 9. A clear O 1s line confirms that a thin oxide layer exists on the surface of $\mathrm{VN}$. The oxygen signal is fitted with two peaks. The main component is centered at $530.3 \mathrm{eV}$ and is typical for oxygen in a metal oxide. The second small peak is at about $531.8 \mathrm{eV}$ and can be attributed to the signal from $-\mathrm{OH}$ groups chemisorbed at the surface. The $\mathrm{BE}$ of such a feature is typically $1.3-1.6 \mathrm{eV}$ higher than that of an oxide in an XPS spectrum. The $\mathrm{V} 2 \mathrm{p}^{3}$ line was fitted with three peaks. The peak at $513.9 \mathrm{eV}$ belongs to vanadium in the vanadium nitride structure. Two other features composing the $\mathrm{V} 2 \mathrm{p}^{3}$ line are centered at 515.0 and $517.2 \mathrm{eV}$ and, most likely, correspond to $\mathrm{V}^{3+}$ and $\mathrm{V}^{5+}$ oxidation states of vanadium in surface oxides. The composition of the surface oxides is different from that in the previous study ${ }^{9}$ where the $\mathrm{V} 2 \mathrm{p}^{3}$ line was a combination of the nitride peak at $514.1 \mathrm{eV}$ and the second feature centered at $516.3 \mathrm{eV}$. The latter is likely to be related to the $\mathrm{V}^{4+}$

(16) Moulder, J. F.; Stricle, W. F.; Sobol, P. E.; Bomben, K. D. Handbook of x-ray photoelectron spectroscopy; Perkin-Elmer Corporation, Physical Electronics Division: 1995.

(17) Bondarenka, V.; Grebinskij, S.; Mickevicius, S.; Tvardauskas, H.; Kaciulis, S.; Volkov, V.; Zakharova, G.; Pasiskevicius, A. Lithuanian J. Phys. 2007, 47, 333. 
oxidation state of vanadium. The value $516.3 \mathrm{eV}$ fits well into the typical range of binding energies for $\mathrm{V}^{4+}(515.6 \pm$ $\left.0.5 \mathrm{eV}^{17}\right)$.

The passivation with an inert gas containing a small amount of $\mathrm{O}_{2}(0.1-2 \%)$ is an established procedure for VN materials in the field of catalysis. ${ }^{10-12}$ Choi et al. used this approach (particularly, a gas mixture of $0.1 \% \mathrm{O}_{2}$ in $\mathrm{Ar}$ ) for passivation of $\mathrm{VN}$ supercapacitors in ref 9 . The same procedure is intentionally applied in this study to control the surface functionalities of vanadium nitrides. However, according to the XPS data and lower values of capacitances achieved, the composition of the surface layer of $\mathrm{VN}$ is different. The $\mathrm{V}^{5+}$ and $\mathrm{V}^{3+}$ states are dominant at the surface of nitride in the current study while $\mathrm{V}^{4+}$ is the most likely oxidation state observed for vanadium in the previous publication. ${ }^{9}$ The surface chemistry can be sensitive to a number of parameters such as the temperature of passivation, oxygen content in the gas, surface area, and pore structure of a nitride. Further research is needed to find reliable methods to control the surface composition of vanadium nitrides and, as a consequence, their capacitances. The prospective VN material for electrochemical capacitors should combine a fine-tuned nitride crystalline structure (for a good highrate performance) and a fine-tuned composition of the surface oxygen-containing layer.

\section{Conclusions}

We have evaluated the structural characteristics and electrochemical properties of vanadium nitride synthesized by $\mathrm{NH}_{3}$ reduction of a $\mathrm{V}_{2} \mathrm{O}_{5}$ powder for its potential application in supercapacitors. VN material forms via a pseudomorphic process: its morphology mimics the shape of the initial $\mathrm{V}_{2} \mathrm{O}_{5}$ precursor, indicating the direct attachment of grains in the polycrystalline structure formed. Crystalline domains with texture (preferential grain orientation) are detected in $\mathrm{VN}$; the [110] crystallographic direction tends to be parallel to the [010] direction in the initial precursor. A large volume of pores within a range of $15-110 \mathrm{~nm}$ is observed.

Vanadium nitride produced by $\mathrm{NH}_{3}$ reduction of $\mathrm{V}_{2} \mathrm{O}_{5}$ has an acceptable rate capability in three aqueous electrolytes- $1 \mathrm{M} \mathrm{H}_{2} \mathrm{SO}_{4}, 1 \mathrm{M} \mathrm{KOH}$, and $3 \mathrm{M} \mathrm{NaCl}$ solutions. VN demonstrates about $80 \%$ of its maximal capacitance at the current rate of $1 \mathrm{~A} / \mathrm{g}$ in galvanostatic charging/discharging experiments in all electrolytes. The negative effect of material loading on the value of capacitance of $\mathrm{VN}$ is suppressed: thick films of $\mathrm{VN}$ can retain high capacitances. The capacitance of $186 \mathrm{~F} / \mathrm{g}$ is achieved at the rate of $1 \mathrm{~A} / \mathrm{g}$ in $1 \mathrm{M} \mathrm{KOH}$ electrolyte. The values of capacitance are believed to be limited by the structure and composition of the surface oxide layer of vanadium nitride. The finetuning of both the crystalline structure of the nitride and the surface composition of the oxygen-containing layer is important for the creation of an efficient nanostructured VN material for supercapacitors.

Acknowledgment. This research was supported by the Centre of Excellence program of the Australian Research Council. The authors thank Dr. John Fitz Gerald, Dr. Cheng Huang, Dr. Bill Bin Gong, and Mr. Tom Cheng for their assistance. 